\title{
Stressors and well-being in low socio-economic status Malaysian adolescents: The role of resilience resources
}

\author{
Noraini M. Noor and Azlin Alwi \\ Department of Psychology, International Islamic University Malaysia, Kuala Lumpur. Malaysia
}

The present study examined the relationship between stressors, resilience resources, and well-being in adolescents with low socio-economic status in Malaysia. The specific aims were: (i) to differentiate between resilient and non-resilient adolescents in terms of their resilience resources; and (ii) to examine the role of resilience resources on the relationship between stressors and well-being. In a sample of 197 adolescents aged 12-16 years (mean $=13.77, s d=1.49$ ), results of the $k$-mean clustering technique identified $37.5 \%$ of the adolescents as resilient (high stressor, high well-being), 31.0\% as maladjusted (high stressor, low well-being), and the rest, adapted (low stressor, high well-being). Resilient adolescents were found to have significantly higher scores on all the identified resilience resources (personality, mother-child communication, social support, school coherence, and teacher support) compared to the non-resilient maladjusted group. Results of structural equation modelling also showed that these resilience resources acted both as mediator and moderator in the relationship between stressors and well-being. These findings are discussed with respect to the current literature on resilience and well-being.

Key words: adolescents, resilience, resilience resources, stressors, well-being.

\section{Introduction}

Resilience research in young people is fast expanding to take into account multiple levels of analysis and perspectives consistent with an integrated system model (see Cicchetti, 2010; Sapienza \& Masten, 2011). The concept of 'resilience', while originating from studies of children at risk for psychotherapy, has been instrumental in understanding what makes some individuals able to adapt while others potentiate towards the reverse. To be defined as resilient, two key criteria are essential: (i) that significant adversity or threat to adaptation has occurred; and (ii) that functioning or development is satisfactory despite adversity (Brooks \& Goldstein, 2002; Masten \& Powell, 2003; Wright \& Masten, 2005). In this context, individuals are not considered resilient if they have never experienced a significant threat/risk to their development (Masten, 2001). While risk factors are associated with developmental problems (Bond, Toumbourou, Thomas, Catalano \& Patton, 2005; Li, Nussbaum \& Richards, 2007; Lussier, Derevensky, Gupta, Bergevin \& Ellenbogen, 2007), protective factors block or reduce the negative impact of risk factors. The more protective factors are available to adolescents, the more resilient they are likely to be (Brooks \& Goldstein, 2002).

Sapienza and Masten (2011) identified four waves in resilience research. The first was descriptive - identifying

Correspondence: Noraini M. Noor, Department of Psychology, International Islamic University, Jalan Gombak, 53100 Kuala Lumpur. Malaysia. Email: noraini@iium.edu.my

Received 26 September 2012; accepted 1 April 2013. resilience resources; the second considered the process underlying resilience functioning; the third promoted resilience intervention programs in individuals experiencing adversity; and the fourth focused on interaction across many levels, ranging from genes to environment. In this final trend, studies consider the neuroscience of resilience or the role of genes in mitigating environmental risks, but these studies are only just beginning (see Cicchetti, 2010; Sapienza \& Masten, 2011). In addition, more research is integrating the study of resilience across system levels to promote better adaptation of adolescents (Bond et al., 2005; Lee, Kwong, Cheung, Ungar \& Cheung, 2010; Leontopoulou, 2006; Li et al., 2007; Salami, 2010). These system levels recognize all aspects of the individual's life as a total entity which affects resilience. This approach places greater emphasis on the role of relationships and systems beyond the family, and attempts to consider and integrate biological, social, and cultural processes into models and studies of resilience (Masten, 2001).

In the Malaysian context, factors predicting resilience can be context- and culture-specific. To many Malaysian adolescents, relationship with families is of utmost importance due to their cultural and religious upbringing (e.g. Baharudin \& Zulkefli, 2009; Tam \& Yusooff, 2009). As revealed by Sheau et al. (2011), family support remains the primary source of social support. Adolescents too are bound to traditional family values such as extreme respect and obedience (Mahmud, Ibrahim, Amat \& Salleh, 2011). As such, they may find it difficult to discuss personal concerns with parents and this usually results in one-way communication from parents to children (Mahmud \& Amat, 
2002). As a result, adolescents normally turn to their peers, teachers, or other significant adults for support (Baharudin \& Zulkefli, 2009). According to Baharudin and Zulkefly (2011), secure attachment relationships promote adolescents' positive school functioning behaviour by increasing self-esteem and feelings of school connectedness, and decreasing problematic behaviour. Li, Martin, Armstrong and Walker (2011) also argued that resilience resources should consider various aspects of adolescents' development. As reiterated by Tam and Yusooff (2009), factors found within the family, the school environment, and society are central to adolescents' well-being. In line with the systems approach, the present study considers three levels of resilience resources (individual, family, and environment) and examines how they influence the stressorstrain relationship in adolescents. Before considering the hypotheses of the present study, a review of the relevant literature is first presented.

\section{Stress in adolescents}

Young people must experience unavoidable change, including physical changes, school transitions, emerging sexuality, and changes in relationships with parents and peers (McMahan, 2009). These changes, known as normative stressors, relate to physical changes (e.g. Steinberg, 2008) and the pressure to establish a sense of identity (e.g. Hankins, Roberts \& Gotlib, 1997), and they can be stressful to some adolescents.

In addition, a host of events and circumstances within the environment places demands on adolescents. Also referred to as non-normative stressors, these stressors exist in the domains of family, school, peers, and community, including unexpected demanding negative life events such as illness, injury, friendship break-ups, parental conflicts, including divorce (Coleman \& Hendry, 2006).

The experience of daily hassles (i.e. minor stressors) can also be damaging to the well-being of adolescents (Guthrie, Young, Boyd \& Kintner, 2001; Sim, 2000). Research reveals that the vast majority of daily stressors experienced by adolescents are the result of everyday interactions that lead to conflicts within the family (Harvey \& Byrd, 2000; Seiffge-Krenke, Weidemann, Fentner, Aegenheister \& Poeblau, 2001) or with friends (Anders \& Tucker, 2000; Bowker, Bukowski, Hymel \& Sippola, 2000) as well as issues associated with initiating and maintaining romantic relationships (Furman, 2002; Nieder \& Seiffge-Krenke, 2001; Pollina \& Snell, 1999).

These various stressors influence how adolescents think and feel (Coleman \& Hendry, 2006; Lerner, 2002; Steinberg, 2008), which inadvertently leads to profound and detrimental impacts on their physical and mental health (Garbarino, 1998; Hyman, 1997; Morales, 2000). Many are highly susceptible to stress, which often results in negative outcomes, particularly when there is a lack of resources or the necessary skills to cope with these stressors (Ang \& Huan, 2006; Feldman, 2008; Tiet et al., 2001). Given the observed importance of multiple types of stressors, the present study included two assessments of stressors: the number of negative life events experienced and perceived daily stressors.

\section{Resilience resources}

The study of resilience is especially significant during adolescence because of the many challenges adolescents face during this period (physical, emotional, and social). Research has shown that resilient adolescents tend to develop into competent adults with high levels of selfefficacy (Werner \& Smith, 1982), high self-control (Alvord \& Grados, 2005), the ability to distance themselves from risk (Drapeau, Saint-Jacques, Lépine, Bégin \& Bernard, 2007), and a decreased risk of depression (Bonanno, Galea, Bucciarelli \& Vlahov, 2007).

Three sets of resilience resources have been identified by past research. At the individual or person level, these include attributes of the adolescents such as personality (Annalakshmi, 2008; Campbell-Sills, Cohan \& Stein, 2006; Davey, Eaker \& Walters, 2003) as well as the learning, thinking, and executive systems (autonomy, social competence, problem-solving skills, and a sense of purpose - see Brackenreed, 2010; Masten \& Garmezy, 1985).

The next level relates to aspects of the individual's family, notably the relationship between adolescents and parents/caretakers. It has been shown that attachment experiences in early life are associated with later adaptation and mental health (Lamb, Thompson, Gardner, Charnov \& Estes, 1984), especially aggression and externalizing behaviour problems (Loeber \& Hay, 1997). Indeed, a recent meta-analytic study of 69 samples $(n=5947)$ found that insecure and disorganized attachments increase the risk of externalizing problems (Fearon, Bakermans-Kranenburg, Van IJzendoorn, Lapsley \& Roisman, 2010). Thus, amongst the family factors associated with resilience are good parental relationships (Ben-Zur, 2003), family functioning (Corcoran, 2001), good parent-child communication (Rosnati \& Marta, 1997), quality of parenting (Armstrong, Birnie-Lefcovitch \& Ungar, 2005), and family discussions (Nurmi \& Pulliainen, 1991). Effective parenting and care leads to the development of a warm, secure, and cohesive relationship between the child and parents/caregivers.

The third level of resilience correlates comes from outside the family - teachers, friends, special person, school counsellors, and good neighbours - who can act as potential buffers for vulnerable adolescents (Brewster \& Bowen, 2004). A sense of belonging in schools (Bowen, Richman, Brewster \& Bowen, 1998) also has been found to help adolescents be more resilient. 
Though more recent studies have considered the neuroscience of resilience or the role of genes in mitigating environmental risks, they are only just beginning (see Cicchetti, 2010; Sapienza \& Masten, 2011). These studies emphasized integrating the study of resilience across system levels to promote positive outcomes among adolescents faced with adversity.

\section{Resilience process}

Masten (2001) provided two major approaches to understand how resilience resources operate to promote resilience in the presence of stressors: variable-focused and person-focused. The variable-focused approach examines the relationships between stressors, potential resilience resources, and well-being outcomes. This approach has been used to test for mediating and moderating pathways of the effects of resilience resources on the relationship between stressors and well-being (Masten \& Powell, 2003), but studies have indicated mixed results. While some have found support for resilience resources to act as moderators on the stressor-outcome relationship (e.g. Leontopoulou, 2006; Gardner, Dishion \& Connell, 2008; Wilks, 2008), other studies have failed to do so and showed that resilience resources mediated the relationship between stressors and outcomes (e.g. Ostaszewski \& Zimmerman, 2006; Prelow, Weaver \& Swenson, 2006). Still other studies (e.g. Alriksson-Schmidt, Wallander \& Biasini, 2007) found only cumulative/additive effects of resilience resources on outcome.

The person-focused approach, on the other hand, distinguishes between resilient and non-resilient individuals (Masten \& Powell, 2003). Carbonell, Reinherz and Giaconia (1998) divided adolescents into resilient and non-resilient groups based on their depression level and comparing them on their behavioural, academic, and psychosocial functioning. Striking differences were found among the groups on these measures with the depressed group reporting greater difficulties than the non-resilient group. Similarly, Rouse (2001) categorized resilient and non-resilient adolescents according to measures of academic achievement and grade point average (GPA), and results showed that resilient students differed from nonresilient students on cognitive and social belief as well as on personal trust scales.

Dumont and Provost (1999), investigating the protective role of social support, coping strategies, self-esteem, and social activities on the experience of stress and depression in three groups of adolescents $(n=297$, well-adjusted, resilient, and vulnerable based on their scores on depressive symptoms and frequency of daily hassles), showed that well-adjusted adolescents had the highest self-esteem, followed by resilient and vulnerable adolescents. On antisocial and illegal activities with peers, both resilient and vulnerable adolescents had higher scores than welladjusted adolescents. Finally, resilient adolescents had higher scores on problem-solving coping strategies than adolescents in the two other groups.

Thus, whereas the variable-focused approach considers the relationship between stressors, resilience resources, and outcome, the person-focused approach attempts to identify and compare adolescents who display patterns of resilience from those who do not. Both approaches show similar individual and environmental variables that are able to distinguish between resilient and non-resilient adolescents.

In the Malaysian context, while a number of studies have examined the relationship between stress and well-being among adolescents (e.g. Esfandyari, Baharudin \& Nowzari, 2009; Rahmah \& Shahraniza, 2008), very few have examined resilience among adolescents. In the two available studies, Doshi (2005) found support for the moderating role of resilience resources (self-esteem, coping, competence, parenting behaviour, and social support) on the relationship between risk factor and family functioning as well as children's well-being. Baharudin, Chi and Sin (2010) investigated the effect of single parent families (treated as the risk factor) on their school-going adolescents and found a positive correlation between parenting practices and the academic achievement of adolescents. These two Malaysian studies, however, are limited because they relied on a single risk factor such as ineffective parenting or single-parent families. In addition, neither considered the two approaches simultaneously in studying resilience to determine the relationship among the three variables (stressors, resilience resources, and well-being).

\section{The present study}

According to Compas (2004), the major impediment in resilience research has been the failure to integrate the different levels of analysis. Research focusing on individual analysis (i.e., Dumont \& Provost, 1999; Lam \& McBride-Chang, 2007; Ong, Bergeman, Bisconti \& Wallace, 2006) often ignored the broader context in which development occurs. Likewise, research on socialenvironmental factors (i.e., Bonanno et al., 2007) has not considered individual factors. Since the development of an individual is the result of many interactions, such as interactions with family members, peers, school, and community organizations, resilience cannot be understood or facilitated without consideration of both individual- and environmental-level factors (Riley \& Masten, 2005). Therefore, a systems approach that combines these levels is more appropriate. Taking this approach, the present study included factors at the individual, family, and school levels simultaneously. Here, we extend the person-focused approach by making use of multiple comparisons to identify and compare the profiles of resilient (high stressors, 


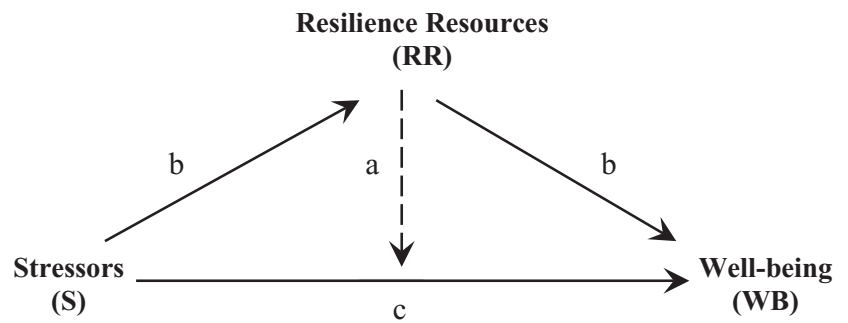

Figure 1 Framework of resilience used in the present study.

Path (a) indicates that Resilience Resources moderates the relationship between Stressors and Well-being.

Path (b) indicates that Resilience Resources mediates the relationship between Stressors and Well-being.

Path (c) indicates the direct effect of Stressors on Well-being.

high well-being) and non-resilient adolescents (low stressors, low well-being) in terms of their levels of resilience resources. To do so, Ong and Bergeman's (2004) resilience framework was used. Figure 1 shows the three main constructs of resilience: stressors, resilience resources, and well-being. Resilience resources include variables at the individual and familial/societal levels.

Based on past studies, we predicted that resilient adolescents would score higher on individual-level factors (measured by personality) as well as on environmental-level factors (measured by social support - from family, friends and teachers, communication with mothers, school coherence) than non-resilient adolescents.

Figure 1 also postulates two pathways in which resilience resources may influence the relationship between stressors and well-being - moderating and mediating. Because past studies (i.e. Alriksson-Schmidt et al., 2007; Masten, 2001; Masten \& Reed, 2002) offered mixed findings regarding how resilience resources influence the stressor-outcome relationship, the second aim of the present study was to examine the possible roles of resilience resources in the relationship between stressors and well-being, using structural equation modelling (SEM). In examining this relationship, researchers have either tested for the moderating impact (e.g. LaFromboise, Hoyt, Oliver \& Whitbeck, 2006; Leontopoulou, 2006; Wilks, 2008) or the mediating impact of resilience resources (e.g. Ju \& Lee, 2008; Prelow, Weaver \& Swenson, 2006; Sandler, 2001). While some have found support for resilience resources to act as moderators in the stressor-outcome relationship (e.g. Gardner et al., 2008; Leontopoulou, 2006; Wilks, 2008), other studies have failed to do so and instead showed that resilience resources mediated the relationship between stressors and outcome (e.g. Ang \& Huan, 2006; Ju \& Lee, 2008; Prelow et al., 2006). By using SEM, the present study would be able to examine multiple variables and relationships simultaneously, to ascertain the role of these resilience resources.

\section{Method}

\section{Participants and procedures}

Participants were drawn from four secondary schools in Sarawak, Malaysia. In this study, the criteria used for participant selection were similar to those used by Masten and Reed (2002), namely: (i) that they came from adverse family backgrounds (low socio-economic status [SES] or broken homes) to indicate 'high stressor'; and (ii) that they performed well in their studies indicating 'high wellbeing'. To select participants, teachers (because they had access to the students' records) were asked to select students from adverse backgrounds who were also doing well in school. Low SES was applied to students coming from rural areas whose parents may or may not have had a stable income. Other criteria included those whose parents were divorced, or had passed away, or who came from singleparent families. In terms of school, teachers were asked to choose students who were performing well academically (i.e. scoring all or a majority of $\mathrm{A}$ grades in their major examinations) or those who were in good classes. Using these criteria, 197 students aged between 12-16 years (mean $=13.77, s d=1.49)$ were selected. There were 122 $(61.9 \%)$ female and $75(38.1 \%)$ male students, respectively.

Prior to the research, approvals were obtained from the Ministry of Education and the Sarawak State Department of Education. Consent was obtained from all the participants' parents, and questionnaires were handed out once the date and time of the questionnaire administration were confirmed.

\section{Measures}

\section{Stressors}

Two measures were used to assess stressors.

(i) Life Events Checklist. This scale, developed by Brand and Johnson (1982), measures 25 potentially traumatic life events that happened to adolescents in the previous year. Participants were asked to answer 'yes' or 'no' to whether the items on the list had happened to them in the previous year. A high score on the number of negative life events indicates significant negative events experienced during the past year. The scale has an acceptable validity and test-retest reliability (Brand \& Johnson, 1982). Lam and McBride-Chang (2007) reported the scale's $\alpha$ as 0.93. In the present study, the Cronbach alpha value was 0.93 . 
(ii) The Problem Questionnaire. This measure, developed by Seiffge-Krenke (1995), assesses the stressfulness of 64 items that have frequently been named as typical and salient everyday stressors. The participants were asked to indicate the stressfulness of each specific problem, ranging from 1 (not stressful at all) to 5 (highly stressful), with higher scores indicating higher stress. Seiffge-Krenke's (2003) study generated a Cronbach's alpha of 0.84. In the present study, the scale's reliability, as measured by the Cronbach's alpha value, was 0.87 .

\section{Resilience resources}

These were measured by both individual- and environmental-level factors.

(i) International Personality Item Pool. The individuallevel factor was assessed by the International Personality Item Pool (IPIP), developed by Goldberg et al. (2006) to measure the five dimensions of personality: extraversion, agreeableness, conscientiousness, emotional stability, and intellect. Participants completed a 50-item questionnaire on a five-point scale ranging from 1 (strongly disagree) to 5 (strongly agree). In this study, the composite measure was used, with higher scores indicating higher levels of the personality traits. The composite scale and its subscales demonstrated a high level of reliability, $\alpha>0.79$ (Goldberg et al., 2006). In this study, the Cronbach's alpha value was 0.70 .

(ii) Mother-child Communication Scale. This scale, developed by Barnes and Olson (1985) was used to assess adolescents' appraisal of communication with their mothers, including the extent of openness or freedom to exchange ideas, information, and concerns between the generations; the trust or honesty experienced; and the emotional tone (positive or negative) of the interactions between family members. The 20 -item scale was scored on a five-point scale ranging from 1 (strongly disagree) to 5 (strongly agree) with high scores indicating good communication between the participant and his/her mother. Barnes and Olson (1985) reported an internal consistency reliability of 0.90 , the scale based on a national sample of 2465 individuals. In this study, the scale's $\alpha$ value was 0.86 .

(iii) Multidimensional Scale of Perceived Social Support. The Multidimensional Scale of Perceived Social Support (MSPSS) is a 12-item scale which was used to measure perceived support from family, friends, and significant others (Zimet, Dahlem, Zimet \& Farley, 1988). Respondents answered items on a seven-point Likerttype scale $(1=$ very strongly disagree; $7=$ very strongly agree), with high scores indicating high social support. Canty-Mitchell and Zimet (2000) reported a very high internal consistency reliability for the scale $(\alpha=0.93)$. In the present study, the scale's $\alpha$ value was 0.89 .

(iv) Sense of School Coherence Scale. Adolescents' sense of school coherence was assessed by nine items adapted from Bowen et al. (1998). The scale measured the extent to which students felt understood by others at school and able to handle the demands of their school environment. Each item was rated on a three-point continuum from 1 (not like me) to 3 (a lot like me), with high scores indicating a high sense of school coherence. Items were summed to range from a low to high sense of school coherence. The reliability coefficient for the scale was 0.66 (Bowen et al., 1998). In the present study, the Cronbach's alpha reliability was 0.82 .

(v) Teacher Support Scale. This measure, developed by Brewster and Bowen (2004), consists of seven statements assessing teacher support - the degree to which students perceived their teachers to be caring, encouraging, respectful, and helpful. Participants were asked to respond whether the statements were untrue (0) or true (1) with higher scores indicating higher levels of teacher support. The reliability coefficient for this scale, as reported by Brewster and Bowen (2004), was 0.81. In this study, the Cronbach's alpha value was 0.70 .

\section{Well-being}

This was assessed by the following two scales.

(i) The Brief Multidimensional Students' Life Satisfaction Scale. The Brief Multidimensional Students' Life Satisfaction Scale (BMSLSS) was developed to measure life satisfaction among children and adolescents (Valois, Zullig, Huebner \& Drane, 2004). The six-item scale tapped satisfaction with specific life domains such as family, friends, school, and self. Each item was rated on a seven-point scale, ranging from 1 (bad) to 7 (happy), with high scores indicating higher life satisfaction. A coefficient alpha of 0.80 was obtained for the BMSLSS (Zullig, Huebner, Patton \& Murray, 2009). In this study, the scale's reliability was 0.78 .

(ii) General Health Questionnaire. The General Health Questionnaire (GHQ), as developed by Goldberg (1978), identifies breaks in normal functioning rather than life-long traits, covering personality disorders or patterns of adjustment when these are associated with distress. In the present study, the 12-item version was used. Subjects were asked to indicate, on a four-point Likert scale (0-3) scale, the extent to which the items best described how they felt over the previous six weeks. A high score on the GHQ indicates poorer mental health. The scale has been validated against clinical ratings and has been shown to have good 
psychometric properties (Banks, 1983). In the present study, the Cronbach's alpha value was 0.77.

All measures were translated from English to Malay using the back-translation procedure. This procedure consisted of several steps. First, the original measures were translated to Malay. The Malay versions were then translated back to English. Both translations were carried out by different individuals. The back translations and the original translations were compared by a third individual, and those translations that passed the back translation were retained. The final versions were then administered to the sample.

\section{Data analysis}

The means, standard deviations, and intercorrelations of all the variables used in the study were first computed.

The 197 students who participated were to some degree resilient because their teachers identified them as coming from low SES backgrounds but performing reasonably well in school. Because this initial selection was to some degree subjective, the $k$-mean clustering technique was then used to identify resilient adolescents from non-resilient ones based on the mean scores of their stressor and well-being measures (refer to Hair, Black, Babin, Anderson \& Tatham, 2010). $k$-means analysis is a non-hierarchical clustering method that aims to partition observations or cases into ' $k$ ' groups, where each case is assigned to the cluster that has the nearest distance to its centroids (Hair et al., 2010). This technique of assigning individuals to types has been used in past studies (e.g. Akse, Hale, Engels, Raaijmakers \& Meeus, 2004; Kjeldstadli et al., 2006). Based on past literature that has identified three main groups (i.e. resilient, maladaptive, and adapted), the present study set the number of clusters, $k$, to three (see Dumont \& Provost, 1999; Leontopoulou, 2006).

In the present study, the participants were grouped according to their stressor (the Life Events Checklist [LEC] and the Problem Questionnaire [PQ], and well-being scores (the BMSLSS and GHQ-12), with resilient adolescents defined as 'high stressor, high well-being', maladaptive adolescents as 'high stressor, low well-being', and adapted adolescents as 'low stressor, high well-being'. The first step in $k$-means clustering was finding the $k$ centres. In the present study, the SPSS was used to find $k$ cases that were well separated, and these values were used as the initial cluster centres. After these initial cluster centres were selected, each case was assigned to the closest cluster, based on its distance from the cluster centres. After the cases had been assigned to clusters, the cluster centres were recomputed according to all of the cases in the cluster. The clusters were described using the final cluster centres. Oneway analysis of variance (ANOVA) with Tukey's post-hoc tests were then used to determine whether the clusters differed from each other on their stressor and well-being scores. A one-way ANOVA was next conducted to examine differences in the resilience resources scores among the three groups.

Finally, SEM was computed to ascertain the role of resilience resources (i.e. as a mediator or moderator) in the relationship between stressors and well-being. Latent variables were created for stressor (consisting of traumatic life events and the stressfulness of salient everyday stressors), resilience resources (consisting of personality, mother-child communication, perceived support from family, friends, significant others, teacher support, and school coherence) and well-being (life satisfaction and psychological distress). However, before SEM was carried out, confirmatory factor analysis (CFA) for each of the measurement models was conducted separately.

To test for mediation effect, several steps were followed (Awang, 2012). Referring to Figure 1, first, S must have a significant and direct effect on WB. Second, S must have a significant and direct effect on RR. Third, RR must have a significant and direct effect on WB. Finally, when RR is controlled, if the relationship between $\mathrm{S}$ and WB is reduced or is no longer significant, then mediation is said to have occurred.

To test for the moderator role of resilience resources (RR), the following steps were followed (Awang, 2012). First, the RR data was clustered into two groups: Data 1 (Low RR) and Data 2 (High RR). This division into high and low RR was done using the $k$-mean clustering technique. Second, two separate models were developed and named as Models 1 and 2. In Model 1, a constraint was placed to fix the relationship between the constructs of interest (S WB) to be equal to 1. The model was renamed as the constrained model. In Model 2, the relationship coefficient was allowed to be freely estimated. The model was then renamed as the unconstrained model. Third, Model 1 and Model 2 were executed using both data 1 and data 2 separately. Finally, once this was completed, differences in the chi-square values between the constrained and unconstrained models were obtained. If the chi-square value between the constrained and unconstrained model differs by more than the value of the chi-square with 1 degree of freedom, which is 3.84 , then the moderator variable (RR) has a significant moderating effect on the relationship between the constructs in the selected path.

\section{Results}

\section{Means, standard deviations, and intercorrelations among variables}

The means, standard deviations, and intercorrelations among the variables under study are shown in Table 1. As can be seen, the means and standard deviations of the measures are within the normal range, and intercorrelations 


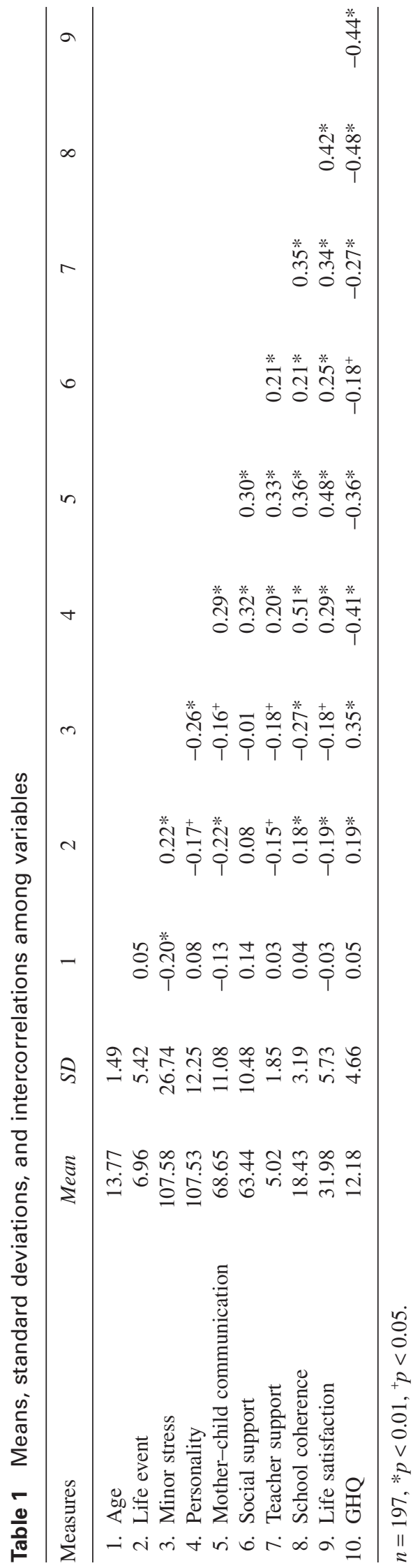

between the variables ranged from low to moderate, except for the relations between personality and school coherence $(r=0.51, p<0.01)$, personality and GHQ $(r=-0.41$, $p<0.01$ ), mother-child communication style and life satisfaction $(r=0.48, p<0.01)$, school coherence and life satisfaction $(r=-0.42, p<0.01)$, school coherence and GHQ $(r=-0.48, p<0.01)$, and between the two outcome measures $(r=-0.44, p<0.01)$.

\section{Comparing resilient and non-resilient adolescents}

The $k$-mean clustering technique yielded 62 (31.5\%) adapted - 'low stressor, high well-being', 61 (31.0\%) maladapted - 'high stressor, low well-being', and 74 (37.5\%) resilient - 'high stressor, high well-being' - adolescents. Figure 2 shows the differences among the three groups based on this analysis. The ANOVA results for the scales were significant, and Tukey's post-hoc tests showed that each cluster was significantly different from the other groups with one exception - for the LEC scale, the only significant difference observed was between the adapted group and maladapted groups (see Table 2). This is not surprising because the LEC items are scored on a range of 0 to 1 , while the other three scales have much more variation (ranging from $0-3$ to $1-7$ ).

The results of this clustering suggest that the resilient group, though experiencing high stressors (as measured only by the PQ) are still able to maintain relatively high well-being (as indicated by both the BMSLSS and GHQ scores).

On the basis of these groupings, one-way analyses of variance were computed to examine the extent to which the three groups differed on the resilience resources. Table 3

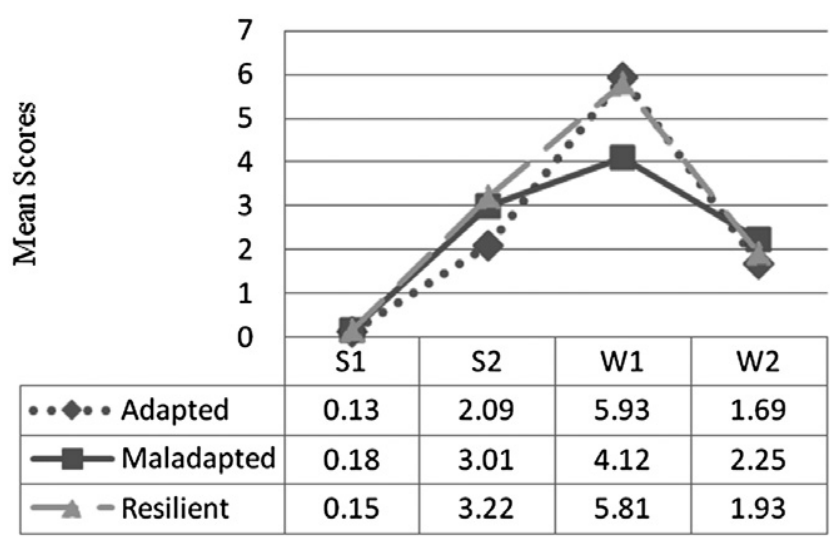

Figure 2 Mean differences among the three groups (adapted, maladapted, and resilient) based on their stressor and well-being scores. ...4., adapted; - maladapted; $\rightarrow-$, resilient.

Note: $\mathrm{S} 1=\mathrm{LEC}, \mathrm{S} 2=\mathrm{PQ}, \mathrm{W} 1=\mathrm{BMSLSS}, \mathrm{W} 2=\mathrm{GHO}$. 


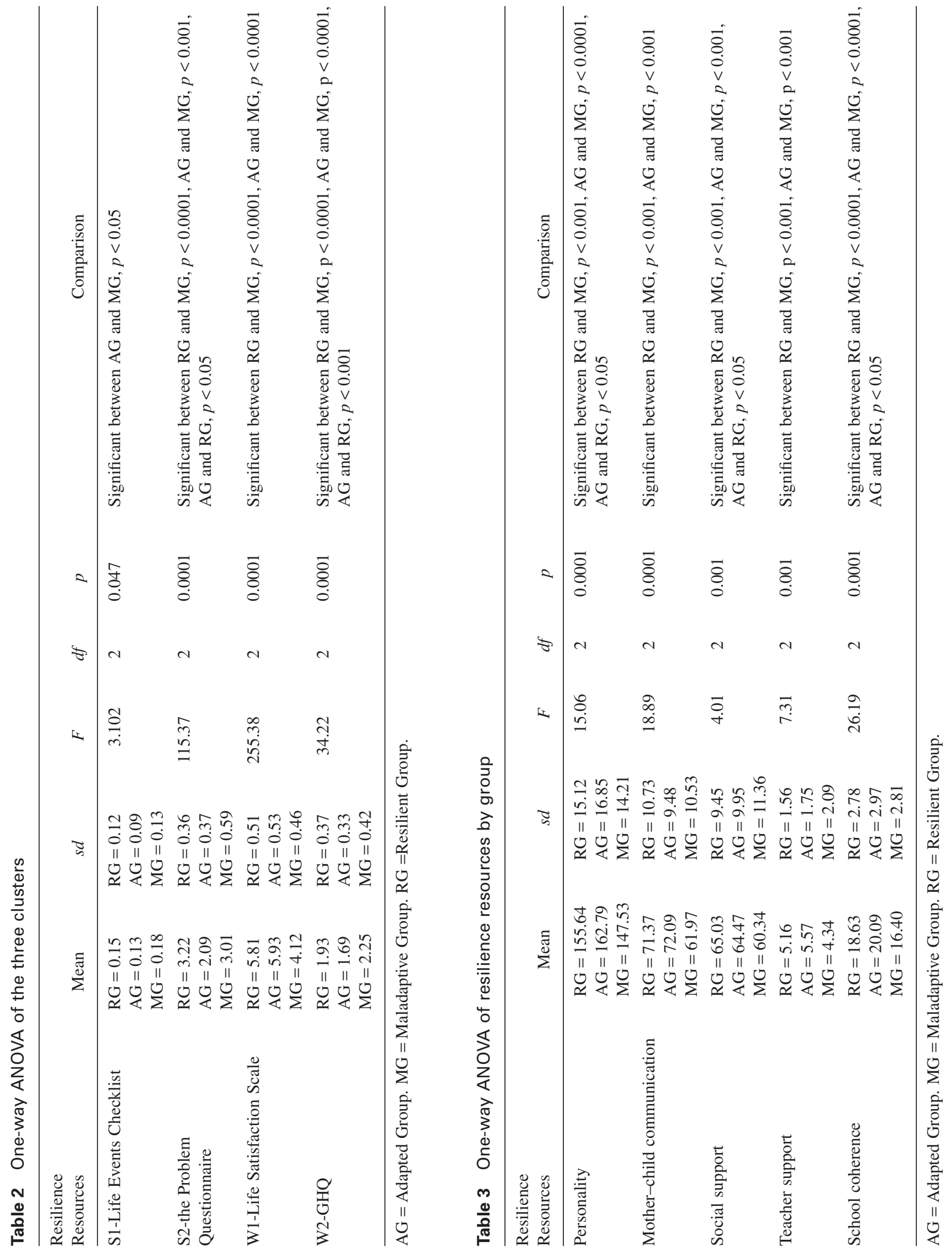


Table 4 The assessment of fitness for the measurement model for all variables

\begin{tabular}{|c|c|c|c|c|c|c|c|c|}
\hline Variables & $\chi^{2}$ & $d f$ & $p$ & RMSEA & GFI & CFI & Normed $\chi^{2}$ & Comment \\
\hline 1. $\mathrm{S} 1$ & 5.80 & 3 & 0.12 & 0.05 & 0.99 & 0.99 & 1.90 & The required level is achieved. \\
\hline 2. $\mathrm{S} 2$ & 57.13 & 27 & 0.00 & 0.07 & 0.94 & 0.95 & 2.10 & \\
\hline 3. $\mathrm{R} 1$ & 8.61 & 4 & 0.07 & 0.07 & 0.98 & 0.97 & 2.15 & \\
\hline 4. $\mathrm{R} 2$ & 48.03 & 27 & 0.01 & 0.06 & 0.90 & 0.96 & 0.18 & \\
\hline 5. R3 & 8.40 & 5 & 0.13 & 0.05 & 0.98 & 0.99 & 1.68 & \\
\hline 6. R4 & 11.15 & 2 & 0.00 & 0.06 & 0.97 & 0.93 & 1.91 & \\
\hline 7. R5 & 26.62 & 13 & 0.14 & 0.07 & 0.96 & 0.93 & 2.05 & \\
\hline 8. WB1 & 1.62 & 1 & 0.20 & 0.05 & 0.99 & 0.99 & 1.62 & \\
\hline 9. $\mathrm{WB} 2$ & 16.60 & 9 & 0.05 & 0.06 & 0.98 & 0.97 & 0.97 & \\
\hline
\end{tabular}

Note: S1 = Life Events Checklist, S2 = The Problem Questionnaire, R1 = International Personality Item Pool, R2= Mother-Child Communication Style, R3 = Multidimensional Scale of Perceived Social Support, R4 = Teacher Support, R5 = Sense of School Coherence, WB1 = The Brief Multidimensional of Students' Life Satisfaction Scale, WB2 = GHQ-12. GFI = Goodness-of-Fit Index. CFI = Comparative Fit Index. RMSEA = Root Mean Square Error of Estimation.

presents the results of the analyses. Significant differences were found for all five resilience resources (see $F$ values, column 4). Post-hoc tests (Tukey HSD) showed that the resilient group differed from the maladapted group on all five resilience resources (last column).

\section{Relationships between stressors, resilience resources, and well-being}

CFA was run separately for every latent construct in the study. These latent constructs were Stressors (LEC and the PQ), Resilience Resources (IPIP, Mother-child Communication Style Scale, MSPSS, Teacher Support Scale, and Sense of School Coherence Scale), and Well-being (BMSLSS and GHQ-12). Based on the CFA results, the number of items in some scales was reduced. The assessments of fitness indices for all the measurement models are presented in Table 4. These indices indicate how well the proposed model captured the covariance among items in the measurement model. As shown in the table, the required levels for all indices were achieved.

Using SEM, the mediator role of resilience resources on the relationship between stressor and well-being was carried out. Table 5 shows the mediation results. As can be seen in the table, when resilience resources were entered with stressors, stressors were no longer significant, but resilience resources remained significant, suggesting a complete mediation effect. The full mediation model is given in Figure 3. The fit indices used, such as GFI (Goodness-of-fit Index), CFI (Comparative Fit Index), and RMSEA (Root Mean Square Error of Estimation; Hair et al., 2010) showed adequate fit to the data, $\chi^{2}[24$, $n=197]=48.50$, normed chi-square $=2.02, \mathrm{GFI}=0.95$, $\mathrm{CFI}=0.95$, RMSEA $=0.07$.

Next, the moderator effect of resilience resources on the relationship between stressor and well-being was tested.
Table 5 Testing mediation effect of resilience resources on well-being

\begin{tabular}{lrcc}
\hline & B & SE B & \multicolumn{1}{c}{$\beta$} \\
\hline $\begin{array}{l}\text { Direct effect: } \\
\quad \text { Stressor }\end{array}$ & -1.26 & 0.16 & $-0.74^{* * *}$ \\
Testing mediation effect: & & & \\
$\quad$ Stressor & -0.18 & 0.56 & 0.10 \\
$\quad$ Resilience resources & 3.12 & 1.21 & $0.96^{* *}$ \\
\hline
\end{tabular}

$* * p<0.001 . \mathrm{B}=$ unstandardized regression coefficient. $\beta=$ standardized regression coefficient.

The output for the constrained and unconstrained models at high and low resilience resources is presented in Table 6 . As shown in the table, moderation effects are observed at both high and low resilience resources. Next, the standardized beta estimates at high and low resources were obtained to determine in which group the moderator effect was more pronounced. Table 7 shows that the moderating effect of resilience resources on the stressor-well-being relationship is more pronounced in the high resources group (slope $=0.97, p<0.01)$.

\section{Discussion}

Resiliency refers to positive outcomes despite the presence of stressors faced by some adolescents. Extensive research focusing on the key resources that are important in enhancing adolescents' resilience suggests that resilience is influenced by individual and social-environmental factors (Armstrong et al., 2005; Brewster \& Bowen, 2004; Campbell-Sills et al., 2006). As a result, studies of resilience are contextualized in multiple ways, including how the individual interacts with many other systems at many 


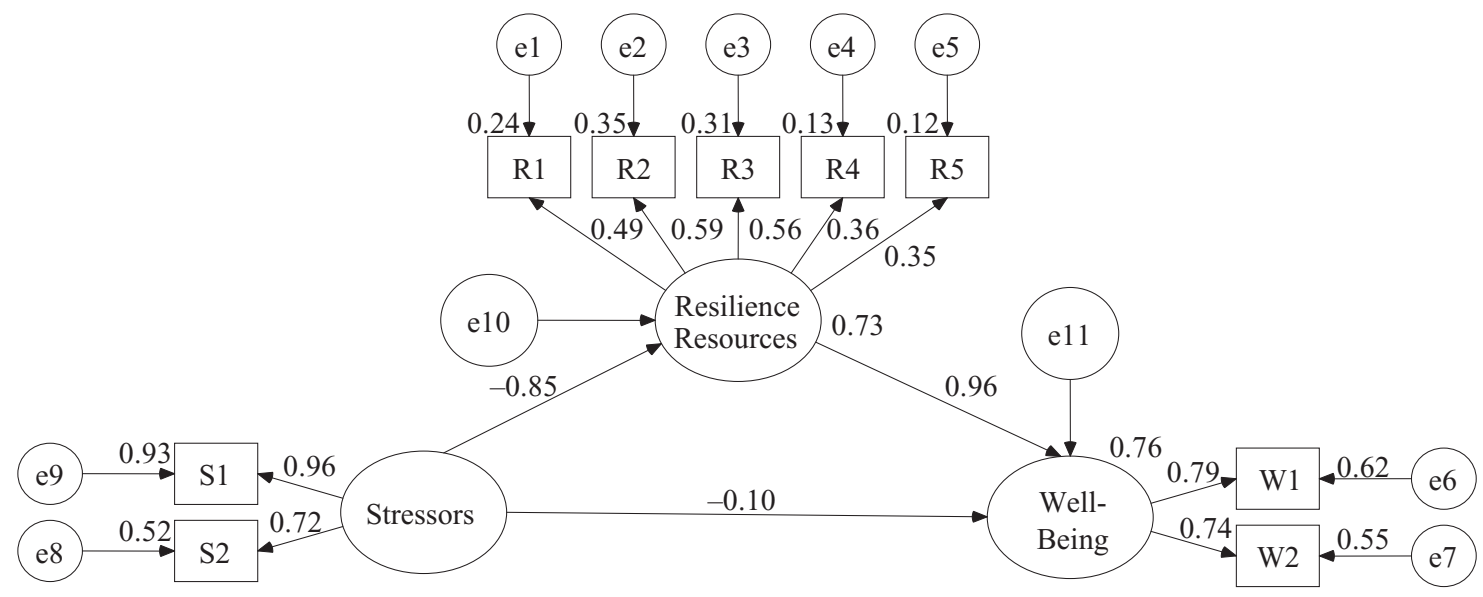

Figure 3 The mediation model.

Chi-square $=48.50, \mathrm{df}=24, p=0.002, \mathrm{GFI}=0.952, \mathrm{CFI}=0.952, \mathrm{AGFI}=0.910, \mathrm{RMSEA}=0.072$, and normed chi square $=2.021$.

Table 6 The moderation test using low and high resources group data

\begin{tabular}{|c|c|c|c|c|c|c|c|c|}
\hline & \multicolumn{4}{|c|}{ Low resources } & \multicolumn{4}{|c|}{ High resources } \\
\hline & $\begin{array}{l}\text { Constrained } \\
\text { model }\end{array}$ & $\begin{array}{c}\text { Unconstrained } \\
\text { model }\end{array}$ & $\Delta \chi^{2} \dagger$ & Result & $\begin{array}{c}\text { Constrained } \\
\text { model }\end{array}$ & $\begin{array}{l}\text { Unconstrained } \\
\text { model }\end{array}$ & $\Delta \chi^{2} \dagger$ & Result \\
\hline$\chi^{2}$ & 97.88 & 91.94 & 5.94 & Significant & 77.37 & 71.49 & 5.88 & $\overline{\text { Significant }}$ \\
\hline Df & 50 & 48 & & & 50 & 48 & & \\
\hline GFI & 0.93 & 0.95 & & & 0.92 & 0.93 & & \\
\hline AGFI & 0.90 & 0.89 & & & 0.86 & 0.86 & & \\
\hline CFI & 0.92 & 0.95 & & & 0.90 & 0.91 & & \\
\hline RMSEA & 0.06 & 0.05 & & & 0.05 & 0.05 & & \\
\hline$\chi^{2} / \mathrm{df}$ & 1.95 & 1.91 & & & 1.54 & 1.49 & & \\
\hline
\end{tabular}

$\dagger \Delta \chi^{2}$ should be $>3.84$.

Table 7 The standardized beta estimate

\begin{tabular}{lcl}
\hline & Standardized beta estimate & $p$ \\
\hline Moderation effect: & & \\
Low resilience resources & 0.87 & 0.90 \\
High resilience resources & 0.97 & 0.002 \\
\hline
\end{tabular}

levels throughout life (Wright \& Masten, 2005). The present study was carried out to: (i) compare between resilient and non-resilient adolescents in terms of their resilience resources; and (ii) examine the role of resilience resources on the relationship between stressors and wellbeing. These results are discussed accordingly.

\section{Resilient versus non-resilient adolescents}

In the present study, teachers initially identified the adolescents based on their low SES backgrounds but good results at school. As this initial selection may be subjective, $k$-mean clustering was used to cluster adolescents who were more resilient, defined as those who have more stressors but are still able to maintain relatively high well-being than those who are less resilient or maladapted (those having more stressors and experiencing low well-being). Consistent with past findings, compared to the maladapted group, resilient adolescents reported significantly higher scores on the five resilient resources (personality, parent-child communication style, social support, school coherence, and teacher support) measured in the present study (e.g. Hawkins, Graham, Williams \& Zahn, 2009; Leontopoulou, 2006; Li et al., 2011). Past studies have also found that resilient adolescents score higher than the maladaptive group on personality (Annalakshmi, 2008; Campbell-Sills et al., 2006; Davey et al., 2003). Resilient adolescents also perceived good teacher support and draw from this resource to face adversity (Brackenreed, 2010). 
The present study showed that these adolescents still place great significance on their family and school/peer relationships. This is so because the society in Sarawak, where the sample was taken, may be considered more traditional regarding familial relationships, where respect and reverence for elders is still strong. This finding is supported by another study that found intergenerational relationship among rural Malaysians to be stable and amicable (Abdul Aziz \& Yusooff, 2012). Children showed positive and responsible attitudes towards their parents and elderly people in the family and community. However, as they get older, parental monitoring and control decline and are replaced by peers and schools (Li et al., 2011). In addition, the sample was made up of young adolescents (12-16 years) who were still quite attached to their families, and this could be another reason for the findings (Mahmud et al., 2011). Therefore, whether the same finding will be replicated in older, more urbanized, higher SES adolescents in the country is unknown.

It is also evident in the present context that adolescents cannot stand alone (on the internal attributes) to acquire resilience. Instead, other factors at the socialenvironmental levels play an important role in strengthening their resilience. The failure to establish a stable and satisfying sense of social relatedness is linked to the development of mental health or social problems, which is especially critical during adolescence.

Thus, by including resources from within themselves (personality) and outside variables from family (mother child communication), support from significant others (social support) as well as school support (school coherence and teacher support), this study was able to overcome one of the limitations of past studies that have considered only individual or environmental resources to show that resilience resources at all three levels are beneficial.

\section{Resilience process}

Having established the number of resources that influence resilience, the present study examined how resilience resources work with stressors to produce positive outcomes. Previous studies have indicated mixed findings on how resilience resources influence the stressor-outcome relationship. While some have found support for the moderating role of resilience resources (Akse et al., 2004; Leontopoulou, 2006; Wilks, 2008), others have established the mediator role of resilience resources in stress-outcome relationships (Ang \& Huan, 2006; Chang, D'Zurilla \& Sanna, 2007; Ju \& Lee, 2008; Prelow et al., 2006). Still other studies have found only direct effects of the role of resources on well-being (Armstrong et al., 2005; Bond et al., 2005; Tiet et al., 2001).

Many past studies have supported either a mediating (e.g. Ju \& Lee, 2008; Ostaszewski \& Zimmerman, 2006; Prelow,
Weaver \& Swenson, 2006) or moderator (e.g. Leontopoulou, 2006; Gardner, Dishion \& Connell, 2008; Wilks, 2008) role of resilience resources. Usually, those testing for the moderator role have utilized multiple regression analysis while those testing for the mediator role have tended to use SEM. Few have tested for both. In the present study, both mediation and moderator pathways were examined using SEM, where latent variables made up of multiple measures of stressors, resilience resources, and well-being were created to simultaneously assess their relationship. In this more rigorous analysis, both the mediator and moderator pathways of resilience resources on the stressor-well-being relationship were observed.

As a mediator, resilience resources improve the outcome or well-being of adolescents. According to Masten (2001), a mediating effect in variable-oriented models theoretically reflects the independent contribution of risks or assets on outcome. In the present study, the cumulative effects of several resilience resources across different levels (personality, family, and school) may be even more helpful in increasing adolescents' assets in contributing to their well-being.

On the other hand, when resilience resources act as moderator, some type of shielding from the effects of risk or adversity is implied. Known also as 'protective' factors (Masten, 2001), they specifically moderate the impact of adversity on adaptation. In the present study, certain qualities within the adolescent and the environment decrease susceptibility to the threatening situation (Masten \& Reed, 2002). While the results show that resilience resources act as moderator for both the high and low resources group, the moderation effect was more pronounced in the former. This finding is consistent with past resilience research, where those with high resources are found to show high wellbeing, despite facing difficulties. On the basis of these results, interventions could attempt to add risk-activated protection, such as a referral service in schools, or they could also focus on changing the quality of already present moderators, such as efforts to improve parental responses to adolescents who are facing difficulties.

\section{Limitations}

The study has a number of limitations. First, the crosssectional nature of the study renders it difficult to make strong assertions about the causal direction of variables predicting well-being, including resilience resources. However, based on theoretical and past research in the area, there is enough evidence indicating that low SES, particularly poverty, is a strong correlate of multiple risk factors, which in turn leads to poor adaptation. For example, studies of children who live in extreme or long-term poverty showing poor adaptation years later (e.g. Yates, Egeland \& Sroufe, 2003) tend to support arguments for the adverse 
effects of poverty. More recent neurobiological studies of resilience on disadvantaged children have also suggested that poverty impairs brain development, resulting in increased risks to health and learning (Sapienza \& Masten, 2011). Therefore, in the present study stressors are presumed to precede resources, which in turn precede outcomes. Longitudinal studies would help to provide a better understanding of the different processes relating to stressors, resilience resources, and well-being.

Second, the sample may not be representative of adolescents in general. The students were identified by their teachers based on the two criteria of having adverse background and performing well in class. While this sampling strategy ensured that there were resilient adolescents in the sample, it nevertheless limits the generalizability of the results. The small sample size may also increase type II error. In addition, it is also possible that this sampling strategy may have threatened the internal validity of survey data by limiting the variability in the scores of the resilience resources.

Third, all the measures used in the study were self-reports, subjecting the results to problems of method variance. Other objective measures would strengthen the study (e.g. teacher reports). Or, as indicated by Bonanno and colleagues (Bonanno, Papa, Lalande, Zhang \& Noll, 2005; Bonanno, Rennicke \& Dekel, 2005), the outcome trajectories method, which assesses participants' adjustments (resiliency) by obtaining anonymous ratings from close friends and relatives, can also be used to study resilience. However, these more objective methods sometimes may not be possible, especially when subjective states are assessed. Because what matters to the adolescent is his/her perception of his/her experience, rather than evaluations made by others, selfreports would reflect the importance and significance of the constructs as perceived by the adolescent.

Finally, while the present study included both individualand external-level resources, the internal measure, assessed only by personality, may be somewhat limited. Some researchers have argued that other internal factors such as self-efficacy, self-control, and self-regulation may be more important (Gardner et al., 2008).

\section{Implications and recommendations}

Future studies on resilience should focus on investigating other resources that may promote resilience. These would include individual factors like self-efficacy, self-control, coping, or self-regulatory processes as well as communitylevel measures such as neighbourhood or community support. Although studies have argued that these community factors may play a crucial role in adolescents' development (Gaylord-Harden, Ragsdale, Mandara, Richards \& Petersen, 2007; Hawkins et al., 2009), they have largely been ignored.

Examining periods of developmental transition may be another fruitful area for future research (Vanderbilt-
Adriance \& Shaw, 2008). Developmental transitions, such as the beginning of formal schooling or entering adolescence and adulthood, may prove to be key points for both increased vulnerability and positive change. To illustrate, the different sub-stages (early, middle, and late adolescence) present different developmental issues (Dacey, Kenny \& Margolis, 2004). At the other end of the spectrum, researchers have discussed the importance of turning points, such as marriage or entering the armed forces, in positively changing the life trajectories of individuals at risk (Rutter, 2000).

The results of the present study have important implications for interventions that aim to assist adolescents at risk by identifying resources that may enhance their competence. One of the most basic lessons gleaned from resilience literature is that it can be fostered in so many diverse ways and environments. For example, counsellors working with at-risk adolescents often cannot reduce their vulnerability or reverse their deficits; therefore, intervention should be via programs that focus on creating opportunities to increase resilience using available resources within the home and school systems.

The resilience-based interventions which focus on promoting positive goals and outcomes have many benefits. These benefits include broad appeal to stakeholders, improved morale and motivation, greater effectiveness in reducing problems than a goal focused narrowly on deficits or problems, and greater attention to both the measurement and achievement of positive change (Masten, Cutuli, Herbers \& Reed, 2009). There are numerous ways for adaptation throughout development to occur, and it would be especially interesting to know more about the diverse situations that positive outcomes can be fostered, particularly how adolescents develop competence in the face of adversity. Future studies may reveal more clearly the nature of how resilient adolescents are able to adjust and develop normally under diverse and adverse conditions.

On the basis of their stressor and well-being scores, the present study was able to distinguish between resilient and maladjusted adolescents using the five resilient resources employed. Resilient adolescents scored significantly higher on these resources compared to the maladjusted group, supporting previous findings that resilience is made up of both internal and external processes. The present findings also show that resilience resources can simultaneously act both as mediator and moderator on the stressor-outcome relationship. Notwithstanding the limitations, the study contributes toward a better understanding of the role of resilience resources in adolescent development. The results also suggest that prevention efforts incorporating salient resources that operate across multiple levels may be a beneficial approach when working with adolescents at risk. 


\section{References}

Abdul Aziz, R. \& Yusooff, F. (2012). Intergenerational relationships and communication among the rural aged in Malaysia Asian Social Science, 8, 184-195.

Akse, J., Hale, III, W. W., Engels, R., Raaijmakers, Q. \& Meeus, W. (2004). Personality, perceived parental rejection and problem behavior in adolescence. Social Psychiatry Psychiatric Epidemiology, 39, 980-988.

Alriksson-Schmidt, A. I., Wallander, J. W. \& Biasini, F. (2007). Quality of life and resilience in adolescents with a mobility disability. Journal of Pediatric Psychology, 32, 370-379.

Alvord, M. K. \& Grados, J. J. (2005). Enhancing resilience in children: A proactive approach. Professional Psychology: Research and Practice, 36, 238-245.

Anders, S. \& Tucker, J. (2000). Adult attachment style, interpersonal communication competence, and social support. Personal Relationships, 7, 379-389.

Ang, R. P. \& Huan, V. S. (2006). Academic Expectations Stress Inventory: Development, factor analysis, reliability, and validity. Educational and Psychological Measurement, 66, 522-539.

Annalakshmi, N. (2008). The resilient individual: A personality analysis. Journal of the Indian Academy of Applied Psychology, 34, 110-118.

Armstrong, M. I., Birnie-Lefcovitch, S. \& Ungar, M. T. (2005). Pathways between social support, family well being, quality of parenting, and child resilience: What we know. Journal of Child and Family Studies, 14, 269-281.

Awang, Z. (2012). A Handbook on SEM: Structural Equation Modeling, 5th edn, Kuala Lumpur, Malaysia: Center of Graduate Studies.

Baharudin, R., Chi, Y. H. \& Sin, J. L. (2010). Educational goals, parenting practices and adolescents' academic achievement. Asian Social Science, 6, 144-152.

Baharudin, R. \& Zulkefli, N. (2009). Relationships with father and mother, self-esteem and academic achievement amongst college students. American Journal of Scientific Research, 6, 86-94.

Baharudin, R. \& Zulkefly, S. (2011). Parental attachment, self-esteem and school adolescents in Malaysia. Paper presented in the 12th European Congress of Psychology, 4-8 July 2011, Istanbul, Turkey. [Cited 22 Dec
2011.] Available from URL: http://psasir .upm.edu.my/18149

Banks, M. (1983). Validation of the General Health Questionnaire in a young community sample. Psychological Medicine, 13, 349353.

Barnes, H. L. \& Olson, D. H. (1985). Parent-adolescent communication and the Circumplex model. Child Development, 56, 438-447.

Ben-Zur, H. (2003). Happy adolescents: The link between subjective well-being, internal resources, and parental factors. Journal of Youth and Adolescence, 32, 67-79.

Bonanno, G. A., Galea, S., Bucciarelli, A. \& Vlahov, D. (2007). What predicts psychological resilience after disaster? The role of demographics, resources, and life stress. Journal of Consulting and Clinical Psychology, 5, 671-682.

Bonanno, G. A., Papa, A., Lalande, K., Zhang, N. \& Noll, J. G. (2005). Grief processing and deliberate grief avoidance: A prospective comparison of bereaved spouses and parents in the United States and the People's Republic of China. Journal of Consulting \& Clinical Psychology, 73, 86-98.

Bonanno, G. A., Rennicke, C. \& Dekel, S. (2005). Self-enhancement among highexposure survivors of the September 11th terrorist attack: Resilience or social maladjustment? Journal of Personality and Social Psychology, 88, 984-998.

Bond, L., Toumbourou, J. W., Thomas, L., Catalano, R. F. \& Patton, G. (2005). Individual, family, school and community risk and protective factors for depressive symptoms in adolescents: A comparison of risk profiles for substance use and depressive symptoms. Prevention Science, 6, 73-88.

Bowen, G. L., Richman, J. M., Brewster, A. \& Bowen, N. (1998). Sense of school coherence, perceptions of danger at school, and teacher support among youth at risk of school failure. Child and Adolescent Social Work Journal, 15, 273-286.

Bowker, A., Bukowski, W. M., Hymel, S. \& Sippola, L. K. (2000). Coping with daily hassles in the peer group in early adolescence: Variations as a function of peer experience. Journal of Research on Adolescence, 10, 211-243.

Brackenreed, D. (2010). Resilience and risk. International Education Studies, 3, 111121.

Brand, A. H. \& Johnson, J. H. (1982). Note on reliability of the Life Events Checklist. Psychological Report, 50, 1274.
Brewster, G. L. \& Bowen, A. B. (2004). Teacher support and the school engagement of Latino middle and high school students at risk of school failure. Child and Adolescent Social Work Journal, 21, 47-67.

Brooks, R. \& Goldstein, S. (2002). Raising Resilient Children: Fostering Strength, Hope, and Optimism in Your Child. Toronto: McGraw Hill.

Campbell-Sills, L., Cohan, S. L. \& Stein, M. B. (2006). Relationship of resilience to personality, coping, and psychiatric symptoms in young adults. Behaviour Research and Therapy, 44, 585-599.

Canty-Mitchell, J. \& Zimet, G. D. (2000). Psychometric properties of the multidimensional scale of perceived social support in urban adolescents. American Journal of Community Psychology, 28, 391-400.

Carbonell, D. M., Reinherz, H. Z. \& Giaconia, R. M. (1998). Risk and resilience in late adolescence. Child and Adolescent Social Work Journal, 15, 251-272.

Chang, E., D’Zurilla, T. \& Sanna, L. (2007). Social problem solving as mediator of the link between stress and psychological well-being in middle adulthood. Cognitive Therapy \& Research, 33, 33-49.

Cicchetti, D. (2010). Resilience under conditions of extreme stress: A multilevel perspective. World Psychiatry, 9, 145-154.

Coleman, J. C. \& Hendry, L. B. (2006). The Nature of Adolescence, 3rd edn, New York: Routledge.

Compas, B. E. (2004). Processes of risk and resilience during adolescence: Linking context and individuals. In: R. M. Lerner \& L. Steinberg, eds. Handbook of Adolescent Psychology, 2nd edn, pp. 263-296. New Jersey: Wiley.

Corcoran, J. (2001). Multi-systemic influences on the family functioning of teens attending pregnancy prevention programs. Child and Adolescent Social Work Journal, 18, 37-49.

Dacey, J., Kenny, M. \& Margolis, D. (2004). Adolescent Development, 3rd edn, Ohio, USA: Thomson.

Davey, M., Eaker, D. G. \& Walters, L. H. (2003). Resilience processes in adolescents: Personality profiles, self-worth and coping. Journal of Adolescent Research, 18, 347362.

Doshi, A. P. (2005). Family functioning and child well-being amongst urban Malay single mother families: Influence of risk and protective factors. Unpublished doctoral dissertation. Universiti Putra Malaysia, Kuala Lumpur, Malaysia. 
Drapeau, S., Saint-Jacques, M., Lépine, R., Bégin, G. \& Bernard, M. (2007). Processes that contribute to resilience among youth in foster care. Journal of Adolescence, 30, 449-466.

Dumont, M. \& Provost, M. A. (1999). Resilience in adolescents: Protective role of social support, coping strategies, self-esteem, and social activities on experience of stress and depression. Journal of Youth and Adolescence, 28, 343-363.

Esfandyari, B., Baharudin, R. \& Nowzari, L. (2009). The relationship between interparental conflicts and externalizing behaviour problems among adolescents. European Journal of Social Sciences, 12, 117 122.

Fearon, R. M. P., Bakermans-Kranenburg, M. J., Van IJzendoorn, M. H., Lapsley, A. \& Roisman, G. I. (2010). The significance of insecure attachment and disorganization in the development of children's externalizing behavior: A meta-analytic study. Child Development, 81, 435-456.

Feldman, R. S. (2008). Adolescence. Upper Saddle River, NJ: Pearson Prentice Hall.

Furman, W. (2002). The emerging field of adolescent romantic relationships. Current Directions in Psychological Science, 11, 177-180.

Garbarino, J. (1998). The stress of being a poor child in America. Child and Adolescent Psychiatric Clinics of North America, 7, 105-119.

Gardner, T. W., Dishion, T. J. \& Connell, A. M. (2008). Adolescent self-regulation as resilience: Resistance to antisocial behavior within the deviant peer context. Journal of Abnormal Child Psychology, 36, 273-284.

Gaylord-Harden, N. K., Ragsdale, B. L., Mandara, J., Richards, M. H. \& Petersen, A. C. (2007). Perceived support and internalizing symptoms in African American adolescents: Self-esteem and ethnic identity as mediators. Journal of Youth Adolescence, $36,77-88$.

Goldberg, D. (1978). Manual of the General Health Questionnaire. Windsor, UK: NFER Publishing Company.

Goldberg, L. R., Johnson, J. A., Eber, H. W., Hogan, R., Ashton, M. C., Cloninger, C. R., et al. (2006). The International Personality Item Pool and the future of public-domain personality measures. Journal of Research in Personality, 40, 84-96.

Guthrie, B. J., Young, A. M., Boyd, C. J. \& Kintner, E. K. (2001). Dealing with daily hassles: Smoking and African-American adolescent girls. Journal of Adolescent Health, 29, 109-115.

Hair, J. F., Black, B., Babin, B., Anderson, R. E. \& Tatham, R. L. (2010). Multivariate Data Analysis, 7th edn, Upper Saddle River, NJ: Prentice Hall.

Hankins, B. L., Roberts, J. \& Gotlib, I. H. (1997). Elevated self standards and emotional distress during adolescence: Emotional specificity and gender differences. Cognitive Therapy and Research, 21, 663680.

Harvey, M. \& Byrd, M. (2000). Relationships between adolescents' attachment styles and family functioning. Adolescence, 35, 345356.

Hawkins, S., Graham, P., Williams, J. \& Zahn, M. (2009). Resilient girls: Factors that protect against delinquency. [Cited $12 \mathrm{Sep}$ 2009.] Available from URL: http://www .ojp.usdoj.gov

Hyman, I. (1997). School Discipline Ami School Violence. Boston: Allyn and Bacon.

Ju, S. Y. \& Lee, Y. H. (2008). Child maltreatment and resilience: Mediating effects of cognitive function and social support. The Journal of Child Studies, 29, 127156.

Kjeldstadli, K., Tyssen, R., Finset, A., Hem, E., Gude, T., Gronvold, N., et al. (2006). Life satisfaction and resilience in medical school - a six-year longitudinal, nationwide and comparative study. BMC Medical Education, 6, 48-55.

LaFromboise, T., Hoyt, D., Oliver, L. \& Whitbeck, L. (2006). Family, community, and school influences on resilience among American Indian adolescents in the Upper Midwest. Journal of Community Psychology, 34, 193-209.

Lam, C. B. \& McBride-Chang, C. A. (2007). Resilience in young adulthood: The moderating influences of gender-related personality traits and coping flexibility. Sex Roles, 56, 159-172.

Lamb, M. E., Thompson, R. A., Gardner, W. P., Charnov, E. L. \& Estes, D. (1984). Security of infantile attachment as assessed in the 'strange situation': Its study and biological interpretation. Behavioral \& Brain Sciences, 7, 127-171.

Lee, T., Kwong, W., Cheung, C., Ungar, M. \& Cheung, M. Y. L. (2010). Children's resilience-related beliefs as predictor of positive child development in the face of adversities: Implications for interventions to enhance children's quality of life. Social Indicator Research, 95, 437-453.
Leontopoulou, S. (2006). Resilience of Greek youth at an educational transition point: The role of locus of control and coping strategies as resources. Social Indicators Research, 76, 95-126.

Lerner, R. M. (2002). Adolescence: Development, Diversity, Context, and Application. Englewood Cliffs, NJ: Prentice Hall.

Li, H., Martin, A., Armstrong, D. \& Walker, W. (2011). Risk, protection and resilience in Chinese adolescents: A psycho-social study. Asian Journal of Social Psychology, 14, 269-282.

Li, S. T., Nussbaum, K. M. \& Richards, M. H. (2007). Risk and protective factors for urban African-American youth. American Journal of Community Psychology, 39, 21-35.

Loeber, R. \& Hay, D. (1997). Key issues in the development of aggression and violence from childhood to early adulthood. Annual Review of Psychology, 48, 371-410.

Lussier, I., Derevensky, J. L., Gupta, R., Bergevin, T. \& Ellenbogen, S. (2007). Youth gambling behaviors: An examination of the role of resilience. Psychology of Addictive Behaviors, 21, 165-173.

Mahmud, Z. \& Amat, S. (2002). What do Malaysian adolescents disclose to their parents? Jurnal Pendidikan, Universiti Teknologi Malaysia, 8, 104-114.

Mahmud, Z., Ibrahim, H., Amat, S. \& Salleh, A. (2011). Family communication, sibling position and adolescents' sense of responsibility. World Applied Sciences Journal (Learning Innovation and Intervention for Diverse Learners), 14, 74-80.

Masten, A., Cutuli, J. J., Herbers, J. \& Reed, M.-G. (2009). Resilience in development. In: C. R. Snyder \& S. Lopez, eds. Oxford Handbook of Positive Psychology, pp. 117131. New York: Oxford University Press.

Masten, A. S. (2001). Ordinary magic: Resilience processes in development. American Psychologist, 56, 227-238.

Masten, A. S. \& Garmezy, N. (1985). Risk, vulnerability and protective factors in developmental psychopathology. In: B. B. Lahey \& A. E. Kazdin, eds. Advances in ChildClinical Psychology, pp. 1-52. New York: Plenum.

Masten, A. S. \& Powell, J. L. (2003). A resilience framework for research, policy, and practice. In: S. S. Luthar, ed. Resilience and Vulnerability: Adaptation in the Context of Childhood Adversities, pp. 261-294. New York: Cambridge University Press.

Masten, A. S. \& Reed, M. J. (2002). Resilience in development. In: C. R. Snyder \& S. J. 
Lopez, eds. Handbook of Positive Psychology, pp. 74-88. New York: Oxford University Press.

McMahan, I. (2009). Adolescence. Upper Saddle river, NJ, USA: Allyn \& Bacon.

Morales, E. (2000). A contextual understanding of the process of educational resilience: High achieving Dominican American students and the 'resilience cycle'. Innovative Higher Education, 25, 7-22.

Nieder, T. \& Seiffge-Krenke, I. (2001). Coping with stress in different phases of romantic development. Journal of Adolescence, 24, 297-311.

Nurmi, J. E. \& Pulliainen, H. (1991). The changing mother-child relationship, selfesteem, and intelligence as determinants of orientation to the future during early adolescence. Journal of Adolescence, 14, $35-51$.

Ong, A. D. \& Bergeman, C. S. (2004). Resilience and adaptation to stress in later life: Empirical perspectives and conceptual implications. Ageing International Summer, 29, 219-246.

Ong, A. D., Bergeman, C. S., Bisconti, T. L. \& Wallace, K. A. (2006). Psychological resilience, positive emotions, and successful adaptation to stress in later life. Journal of Personality and Social Psychology, 91, 730-749.

Ostaszewski, K. \& Zimmerman, M. A. (2006). The effects of cumulative risks and promotive factors on urban adolescent alcohol and other drug use: A longitudinal study of resiliency. American Journal of Community Psychology, 38, 237-249.

Pollina, L. K. \& Snell, W. E. Jr (1999). Coping in intimate relationships: Development of the Multidimensional Intimate Coping Questionnaire. Journal of Social and Personal Relationships, 16, 133-144.

Prelow, H. M., Weaver, S. R. \& Swenson, R. (2006). Competence, self-esteem, and coping efficacy as mediators of ecological risk and adjustment in urban African American and European American youth. Journal of Youth and Adolescence, 35, 507517.

Rahmah, M. A. \& Shahraniza, B. (2008). Risk taking behavior among early adolescents in Johor Bahru and its associated factors. Journal of Community Health, 14, 24-30.

Riley, J. R. \& Masten, A. S. (2005). Resilience in context. In: R. D. Peters, B. Leadbeater \&
R. J. McMahon, eds. Resilience in Children, Families, and Communities: Linking Context to Practice, pp. 13-25. New York, NY, USA: Springer.

Rosnati, R. \& Marta, E. (1997). Mother-child relationships as protective factor in preventing adolescents' psychosocial risk in interracial adoptive and non-adoptive families. Journal of Adolescence, 20, 617-631.

Rouse, K. A. (2001). Resilient students' goals and motivation. Journal of Adolescence, 24, 461-472.

Rutter, M. (2000). Resilience reconsidered: Conceptual considerations, empirical findings, and policy implications. In: J. P. Shonkoff \& S. J. Meisels, eds. Handbook of Early Intervention, 2nd edn, pp. 651-681. New York: Cambridge University Press.

Salami, S. O. (2010). Moderating effects of resilience, self-esteem and social support on adolescents' reactions to violence. Asian Social Science, 6, 101-110.

Sandler, I. N. (2001). Quality and ecology of adversity as common mechanisms of risk and resilience. American Journal of Community Psychology, 29, 19-61.

Sapienza, J. K. \& Masten, A. S. (2011). Understanding and promoting resilience in children and youth. Current Opinion in Psychiatry, 24, 267-273.

Seiffge-Krenke, I. (1995). Stress, Coping, and Relationships in Adolescence. Hillsdale, NJ: Lawrence Erlbaum Associates.

Seiffge-Krenke, I. (2003). School-related stress and family stress: Differences in stress perception and coping style in healthy and clinical groups. Psychology, 10, 258269.

Seiffge-Krenke, I., Weidemann, S., Fentner, S., Aegenheister, N. \& Poeblau, M. (2001). Coping with school-related stress and family stress in healthy and clinically referred adolescents. European Psychologist, 6, 123132.

Sheau, T. C., Abdul Rahim, S., Subhi, N., Abdul Kadir, N. B., Jusoff, K., Abdul Talib, M. H., Wan Mahmud, W. A., Peng, K. C., Ismail, R., Mustapha, Z., Mohamed, R. H., Ismail, R., Mustaffa, A. M., Abdul Raop, N., Yusopp, N. R. \& Ismail, S. (2011). Selfintegrity and family support as assets for resilient urban at-risk youth. World Applied Sciences Journal (Special Issues of Social and Psychological Sciences for Human Development), 12, 20-24.
Sim, H. (2000). Relationship of daily hassles and social support to depression and antisocial behavior among early adolescents. Journal of Youth and Adolescence, 29, 647659.

Steinberg, L. (2008). Adolescence, 8th edn, New York: McGraw Hill College.

Tam, C. L. \& Yusooff, F. (2009). The effects of family functioning on self-esteem of children. European Journal of Social Sciences, 9, 643-650.

Tiet, Q. Q., Bird, H. R., Hoven, C. W., Wu, P., Moore, R. \& Davies, M. (2001). Resilience in the face of maternal psychopathology and adverse life events. Journal of Child and Family Studies, 109, 347-365.

Valois, R. F., Zullig, K. J., Huebner, E. S. \& Drane, J. W. (2004). Life satisfaction and suicide among high school adolescents. Social Indicators Research, 66, 81-105.

Vanderbilt-Adriance, E. \& Shaw, D. S. (2008). Protective factors and the development of resilience in the context of neighborhood disadvantage. Journal of Abnormal Psychology, 36, 887-901.

Werner, E. E. \& Smith, R. S. (1982). Vulnerable but Invincible: A Study of Resilient Children. New York: McGraw-Hill.

Wilks, S. E. (2008). Resilience amid academic stress: The moderating impact of social support among social work students. Advances in Social Work, 9, 106-125.

Wright, M. \& Masten, A. S. (2005). Resilience processes in development: Fostering positive adaptation in the context of adversity. In: S. Goldstein \& R. B. Brooks, eds. Handbook of Resilience in Children, pp. 17-37. New York, NY: Kluwer Academic/Plenum Publisher.

Yates, T. M., Egeland, B. \& Sroufe, L. A. (2003). Rethinking resilience: A development process perspective. In: S. S. Luthar, ed. Resilience and Vulnerability: Adaptation in the Context of Childhood Adversities, pp. 234-256. New York: Cambridge University Press.

Zimet, G. D., Dahlem, N. W., Zimet, S. G. \& Farley, G. K. (1988). The Multidimensional Scale of perceived social support. Journal of Personality Assessment, 52, 30-41.

Zullig, K. J., Huebner, E. S., Patton, J. M. \& Murray, K. A. (2009). The brief multidimensional students' life satisfaction scale college version. American Journal of Health Behavior, 33, 483-493. 